\title{
Determination of Theoretical Transition Probabilities for the PB III Spectrum
}

C. Colón

A. Alonso-Medina

\begin{abstract}
Theoretical values of absolute transition probabilities for 54 lines arising from the $6 \mathrm{~s} \mathrm{np}$ configuration of $\mathrm{Pb}$ III have been obtained. These values were obtained in intermediate coupling (IC) and using $a b$ initio relativistic Hartree-Fock calculations. We used for the IC calculations the standard method of least square fitting of experimental en ergy levels by means of computer codes from Cowan. These values, although in general agreement with the rare experimental data, do present some noticeable discrepancies. Analysis of the interaction between ${ }^{1} \mathrm{D}_{2}$ levels of $6 \mathrm{p}^{2}$ and $6 \mathrm{~s} 6 \mathrm{~d}$ configurations shows a $40 \%$ contribution from the $6 s 6 \mathrm{p}^{2}$ configuration for the lowest one, and a $27 \%$ contribution from $6 s 6 d$ for $6 s 6 p^{2}$.
\end{abstract}

\section{Introduction}

Data on atomic properties are relevant not only to spectroscopy, but these values are also of interest in a variety of other fields in physics and technology. In this work we present transition probabilities for the $6 s^{2}-6 s n p$, $6 s n s-6 s n p$ and 6 snd-6snp lines of $\mathrm{Pb}$ III. For these lines there are few published theoretical and experimental results. This has been the motivation for two studies. One is by Colón et al. [1] and presented experimental transition probabilities for 10 lines corresponding to the $6 \mathrm{~s} 7 \mathrm{p}$ level of $\mathrm{Pb}$ III using the emission of a plasma generated by focusing a laser beam on a $\mathrm{Pb}$ target. The second is this theoretical study that was carried out using the relativistic Hartree-Fock calculations with configuration interaction in an intermediate coupling scheme. The Cowan [2] code (1981) was selected for this purpose.

Relativistic Hartree-Fock calculations for Pb III, including a potential model to represent core polarisation, have been reported by Migdalek and Baylis [3,4]. In 1972 Andersen [5] presented a beam foil study of atomic lifetimes showing two strong spectral lines at $1049 \AA$ and 1028 $\AA$ of $\mathrm{Pb}$ III. In 1988 new beam-foil lifetime analyses of the low lying levels in $\mathrm{Pb}$ III were reported (Ansbacher et al. [6] and Pinnington et al. [7]). Recently transition analyses from the autoionizing states $5 \mathrm{~d}^{9} 6 \mathrm{~s}^{2} n \mathrm{f}$ and $5 \mathrm{~d}^{9} 6 \mathrm{~s}^{2} \mathrm{np}$ to the ground state $5 \mathrm{~d}^{10} 6 \mathrm{~s}^{2}{ }^{1} \mathrm{~S}_{\bullet}$ in $\mathrm{Pb}$ III have been reported by Raassen et al. [8].

We shall first describe in Section 2 the theoretical considerations and then in Section 3 the results and discussion.

\section{Theoretical calculations}

In most cases the single configuration and Russell-Saunders scheme is insufficient to describe adequately the $\mathrm{Pb}$ III ion (Desclaux and [9]). A more detailed description is necess- ary to take into account some experimental results for the $6 s 6 \mathrm{~d}$ and $6 \mathrm{~s} 6 \mathrm{p}^{2}$ configurations. We have obtained theoretical values of transition probabilities in intermediate coupling (IC) and using ab initio relativistic Hartree-Fock (HFR) calculations.

For the IC calculations we used the standard method of least-square fitting of experimental energy levels by means of computer codes from Cowan [2]. In this way we obtained the $L S$ composition of each level and the degree of configuration mixing, when we considered their interaction. For the HFR calculations the Cowan computer code provided us with the radial parts for determination of transition probabilities and initial estimates of the parameters for the IC fittings. The radial integrals for calculations of transition probabilities were obtained from the HFR wavefunctions.

The system considered is complex, since at high $Z$ both relativistic and correlation effects are important. Leastsquare fitting of experimental energy levels partially accounts for correlation effects not explicitly calculated in our work.

\section{Results and discussion}

\section{1. $6 p^{2}-6 s 6 d$ configuration interaction}

Levels from the $\mathrm{Pb}$ III 6s6d configurations present some anomalies. The most obvious effect is the relative energy position of the $6 s 6 \mathrm{~d}{ }^{1} \mathrm{D}_{2}$ level. Experimentally this level is found below the ${ }^{3} \mathrm{D}$ levels of this configuration. Corresponding to Hund's rule, in such a configuration the minimum energy would correspond to the triplet levels. A similar situation has already been found in the homologous $4 \mathrm{~s} 4 \mathrm{~d}$ levels in $\mathrm{Zn} \mathrm{I} \mathrm{(Ansbacher} \mathrm{et} \mathrm{al.} \mathrm{[10])} \mathrm{and} \mathrm{in} \mathrm{the} \mathrm{5s5d} \mathrm{state} \mathrm{in} \mathrm{In}$ II ( Martínez et al. [11]). Thus interactions between the $6 \mathrm{~s}^{2}$, $6 \mathrm{~s} 6 \mathrm{~d}$ and $6 \mathrm{p}^{2}$ configurations were introduced in our study.

The energy level positions expected for $6 \mathrm{~s} 6 \mathrm{~d}$ and $6 \mathrm{p}^{2}$ configurations in the absence of interactions can be observed in the left-hand section of Fig. 1. The values of this first diagram come from a theoretical HFR calculation of separated $6 \mathrm{~s} 6 \mathrm{p}^{2}$ and $6 \mathrm{~s} 6 \mathrm{~d}$ configurations with no consideration of their interaction. A comparison between these results and the experimental values (Moore [12]) (the right section of Fig. 1.) shows a large discrepancy.

The second diagram in Fig. 1 shows the effect of allowing for configuration interaction in the HFR calculation. The effect of "energy level repulsion" is clearly significant between $6 \mathrm{p}^{2}{ }^{1} \mathrm{D}$ levels and $6 \mathrm{~s} 6 \mathrm{~d}{ }^{1} \mathrm{D}$ and the $6 \mathrm{~s} 6 \mathrm{~d}{ }^{1} \mathrm{D}_{2}$ level is found correctly below the $6 s 6 \mathrm{~d}{ }^{3} \mathrm{D}$ levels. 


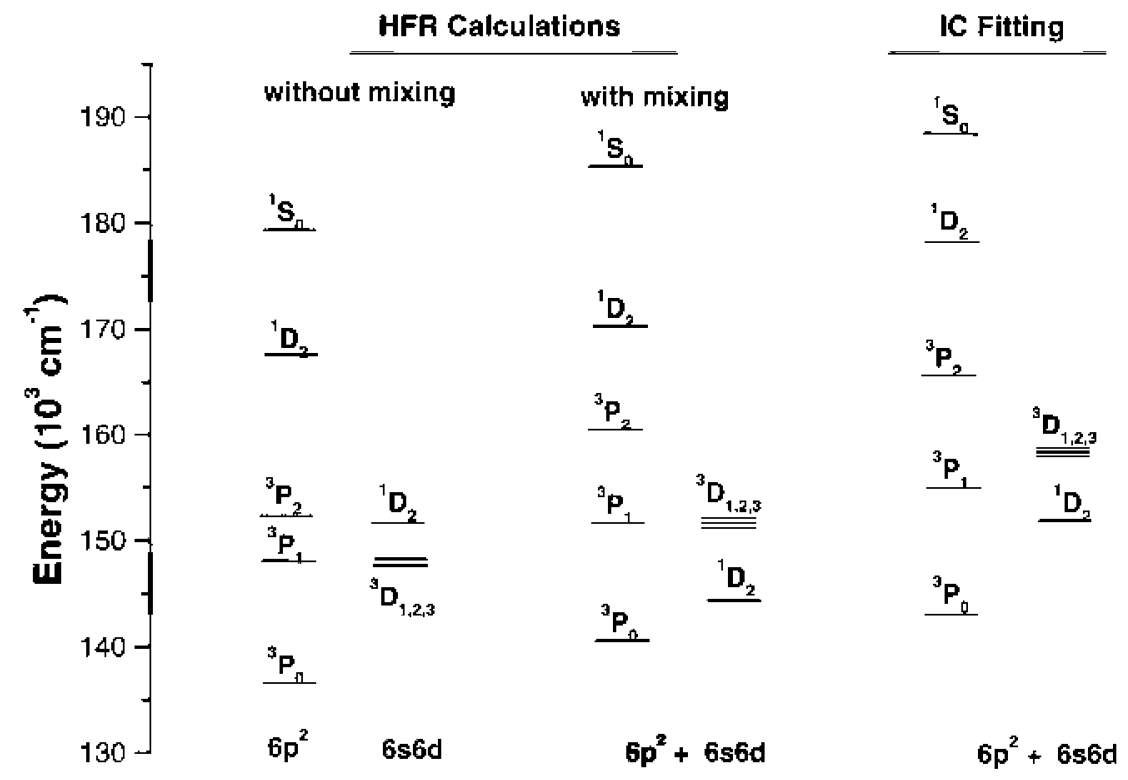

Fig. 1. Effects of $6 p^{2}-6 s 6 d$ configuration interaction. (Experimental situation of energy levels is not shown as they are close to the IC ones).

Table I. Energy levels and configuration mixing effects in Pb III.

\begin{tabular}{|c|c|c|c|c|c|c|c|c|}
\hline \multirow{2}{*}{$\begin{array}{l}\text { Levels } \\
\text { (Moore) }\end{array}$} & \multicolumn{2}{|c|}{ Energy $\left(\mathrm{cm}^{1}\right)$} & \multicolumn{2}{|c|}{ Lande Factor } & \multirow[b]{2}{*}{$J$} & \multicolumn{3}{|c|}{ Composition } \\
\hline & Exp & Cal & Exp & Cal & & $\% 1^{\text {st }}$ comp & $\% 2^{\text {nd }}$ comp & $\% 3^{\text {rd }}$ comp \\
\hline \multicolumn{9}{|l|}{$6 s 6 p$} \\
\hline${ }^{3} \mathbf{P}_{0}$ & 60397 & 60625 & & & 0 & $1006 s 6 p^{3} \mathrm{P}$ & & \\
\hline${ }^{3} \mathbf{P}_{1}$ & 64391 & 64125 & & 1.46 & 1 & $926 s 6{ }^{3} \mathrm{P}$ & $86 s 6{ }^{1} P$ & \\
\hline${ }^{1} \mathbf{P}_{1}$ & 95340 & 95357 & & 1.04 & 1 & 92 6s $6 \mathrm{p}^{1} \mathrm{P}$ & $86 s 6 p^{3} P$ & \\
\hline${ }^{3} \mathbf{P}_{2}$ & 78984 & 78888 & & 1.05 & 2 & 99 6s $6 p^{3} \mathrm{P}$ & $16 s^{2} 6 p^{3} p$ & \\
\hline \multicolumn{9}{|l|}{$6 \mathrm{~s} 7 \mathrm{p}$} \\
\hline${ }^{3} \mathbf{P}_{0}$ & 170917 & 170917 & & & 0 & $1006 \mathrm{~s} 7 \mathrm{p}^{3} \mathrm{P}$ & & \\
\hline${ }^{3} \mathbf{P}_{1}$ & 171081 & 171081 & 1.38 & 1.39 & 1 & 78 6s $7 \mathrm{p}^{3} \mathrm{P}$ & 22 6s $7 \mathrm{p}^{1} \mathrm{P}$ & \\
\hline${ }^{1} \mathbf{P}_{1}$ & 177181 & 177142 & 1.15 & 1.11 & 1 & 77 6s $7 \mathrm{p}{ }^{1} \mathrm{P}$ & 23 6s $7 \mathrm{p}^{3} \mathrm{P}$ & \\
\hline${ }^{3} \mathbf{P}_{2}$ & 176022 & 176053 & 1.34 & 1.50 & 2 & $1006 \mathrm{~s} 7 \mathrm{p}{ }^{3} \mathrm{P}$ & & \\
\hline \multicolumn{9}{|l|}{$6 s 8 p$} \\
\hline${ }^{3} \mathbf{P}_{0}$ & 206809 & 206816 & & & 0 & $1006 \mathrm{~s} 8 \mathrm{p}^{3} \mathrm{P}$ & & \\
\hline${ }^{3} \mathbf{P}_{1}$ & 206979 & 206972 & 1.38 & 1.38 & 1 & 77 6s $8 \mathrm{p}^{3} \mathrm{P}$ & 23 6s $8 \mathrm{p}^{1} \mathrm{P}$ & \\
\hline${ }^{1} \mathbf{P}_{1}$ & 209318 & 209321 & 1.12 & 1.12 & 1 & $776 s 8 p^{1} \mathrm{P}$ & $236 s 8 p^{3} \mathrm{P}$ & \\
\hline${ }^{3} \mathbf{P}_{2}$ & 208922 & 208920 & 1.50 & 1.50 & 2 & $1006 \mathrm{~s} 8 \mathrm{p}^{3} \mathrm{P}$ & & \\
\hline \multicolumn{9}{|l|}{$6 \mathrm{~s} 7 \mathrm{~s}$} \\
\hline${ }^{1} \mathrm{~S}_{0}$ & 153783 & 153784 & & & 0 & $1006 \mathrm{~s} 7 \mathrm{~s}^{1} \mathrm{~S}$ & & \\
\hline${ }^{3} S_{1}$ & 150083 & 150083 & 1.98 & 2.00 & 1 & $1006 \mathrm{~s} 7 \mathrm{~s}^{3} \mathrm{~S}$ & & \\
\hline \multicolumn{9}{|l|}{$6 \mathrm{~s} 8 \mathrm{~s}$} \\
\hline${ }^{1} \mathrm{~S}_{0}$ & 199400 & 199392 & & & 0 & $1006 \mathrm{~s} 8 \mathrm{~s}{ }^{1} \mathrm{~S}$ & & \\
\hline${ }^{3} \mathrm{~S}_{1}$ & 197892 & 197867 & 2.00 & 2.00 & 1 & $1006 \mathrm{~s} 8 \mathrm{~s}^{3} \mathrm{~S}$ & & \\
\hline \multicolumn{9}{|l|}{$6 \mathrm{~s} 7 \mathrm{~d}$} \\
\hline${ }^{3} \mathbf{D}_{1}$ & 201398 & 201399 & 0.50 & 0.50 & 1 & $1006 \mathrm{~s} 7 \mathrm{~d}^{3} \mathrm{D}$ & & \\
\hline${ }^{3} \mathbf{D}_{2}$ & 201597 & 201597 & 1.16 & 1.16 & 2 & $976 \mathrm{~s} 7 \mathrm{~d}^{3} \mathrm{D}$ & $36 \mathrm{~s} 7 \mathrm{~d}^{1} \mathrm{D}$ & \\
\hline${ }^{3} \mathrm{D}_{3}$ & 202046 & 202046 & 1.33 & 1.33 & 3 & $1006 \mathrm{~s} 7 \mathrm{~d}^{3} \mathrm{D}$ & & \\
\hline${ }^{1} D_{2}$ & 203301 & 203301 & 1.00 & 0.98 & 2 & $966 \mathrm{~s} 7 \mathrm{~d}^{1} \mathrm{D}$ & $46 s 7 d^{3} D$ & \\
\hline \multicolumn{9}{|l|}{$6 \mathrm{~s}^{2}+6 \mathrm{p}^{2}+$} \\
\hline \multicolumn{9}{|l|}{$+6 \mathrm{~s} 6 \mathrm{~d}$} \\
\hline${ }^{3} \mathbf{P}_{0}$ & 142551 & 142552 & & & 0 & $856 \mathrm{p}^{2}{ }^{3} \mathrm{P}$ & $156 \mathrm{p}^{2}{ }^{1} \mathrm{~S}$ & \\
\hline${ }^{1} \mathrm{~S}_{0}$ & 188615 & 188615 & & & 0 & $856 \mathrm{p}^{2}{ }^{1} \mathrm{~S}$ & $156 \mathrm{p}^{2}{ }^{3} \mathrm{P}$ & \\
\hline${ }^{3} \mathbf{P}_{1}$ & 155431 & 155431 & & 1.50 & 1 & $1006 \mathrm{p}^{2}{ }^{3} \mathrm{P}$ & & \\
\hline${ }^{3} \mathbf{D}_{1}$ & 157444 & 157395 & 0.50 & 0.50 & 1 & $1006 \mathrm{~s} 6 \mathrm{~d}^{3} \mathrm{D}$ & & \\
\hline${ }^{1} \mathbf{D}_{2}$ & 151884 & 151884 & 1.07 & 1.06 & 2 & $476 \mathrm{~s} 6 \mathrm{~d}^{1} \mathrm{D}$ & $406 \mathrm{p}^{2}{ }^{1} \mathrm{D}$ & $136 \mathrm{p}^{2}{ }^{3} \mathrm{P}$ \\
\hline${ }^{3} \mathbf{D}_{2}$ & 157925 & 158013 & 1.16 & 1.16 & 2 & $986 \mathrm{~s} 6 \mathrm{~d}^{3} \mathrm{D}$ & $16 \mathrm{p}^{2}{ }^{1} \mathrm{D}$ & $16 \mathrm{p}^{2}{ }^{3} \mathrm{P}$ \\
\hline${ }^{3} \mathbf{P}_{2}$ & 164817 & 164819 & 1.40 & 1.31 & 2 & $626 \mathrm{p}^{2} \quad{ }^{3} \mathrm{P}$ & $346 \mathrm{~s} 6 \mathrm{~d}^{1} \mathrm{D}$ & $46 \mathrm{p}^{2}{ }^{1} \mathrm{D}$ \\
\hline${ }^{1} \mathbf{D}_{2}$ & 178432 & 178432 & & 1.14 & 2 & $546 \mathrm{p}^{2}{ }^{1} \mathrm{D}$ & $296 \mathrm{p}^{2}{ }^{3} \mathrm{P}$ & 276 s $6 d^{1} D$ \\
\hline${ }^{3} \mathbf{D}_{3}$ & 158956 & 158922 & 1.33 & 1.33 & 3 & $1006 \mathrm{~s} 6 \mathrm{~d}^{3} \mathrm{D}$ & & \\
\hline
\end{tabular}


Finally, the fitting of experimental energy levels in the IC calculations confirms this situation providing the results than can be seen at the right-hand side of Fig. 1 and in Table I.

The values found for the different parameters involved in the IC calculations are shown in Table II. These calculations can be considered successful and some conclusions must be made at this point. In the first place, the values quoted in Table I show the strong mixing of ${ }^{1} \mathrm{D}_{2}$ levels of both configurations.

Secondly, no configuration mixing can be found in the $J=1$ family. Although relevant amounts of $6 \mathrm{~s} 6 \mathrm{~d}{ }^{1} \mathrm{D}_{2}$ and $6 \mathrm{p}^{2}{ }^{1} \mathrm{D}_{2}$ are found, in the $6 \mathrm{p}^{2}{ }^{3} \mathrm{P}_{2}$ level IC mixing, there is no appreciable amount of ${ }^{3} \mathrm{D}_{2}$ in this composition.

\section{2. $6 s 6 p$ and $6 s 7 p$ configurations}

A discrepancy of about $200 \mathrm{~cm}^{-1}$ remains between experimental and theoretical energy levels values in the case of the $6 \mathrm{~s} 6 \mathrm{p}$ configuration. In comparison, theoretical values of $6 s 7 p$ energy levels, shown in Table I, present a lesser discrepancy with the experimental ones. In both cases, we think that it must have its origin in an interaction with other configurations. Clear evidence for configuration mixing is the existence of the observed $6 s 7 \mathrm{p}-6 \mathrm{p}^{2}$ dipole forbidden transitions. The $6 \mathrm{~s} 6 \mathrm{p}$ and $6 \mathrm{~s} 7 \mathrm{sp}$ IC set can not remove these discrepancies, and there is not an appreciable amount of $6 s 6 p^{3} P_{2}$ in the IC composition of $6 s 7 p^{3} P_{2}$. We have analysed other set candidates but we have found very small perturbations not accounting for the discrepancy. A good example is the $5 \mathrm{~d}^{9} 6 \mathrm{~s}^{2} 6 \mathrm{p}$ configuration for which a decrease in the $6 s 7 \mathrm{p}$ discrepancies was found when treated together with the $6 s 6 p+6 s 7 p$ ones. Nevertheless this set only accounts for about $2 \%$ IC mixing of ${ }^{3} \mathrm{P}_{2}$ levels corresponding to $6 \mathrm{~s} 6 \mathrm{p}$ and $6 s 7 \mathrm{p}$ configurations and cannot explain the $6 s 7 \mathrm{p}-6 \mathrm{p}^{2}$ transitions. Considerations of other candidates with experimentally observed energy levels which might be able to explain this transition, such as $6 \mathrm{p} 7 \mathrm{~s}$ and $6 \mathrm{p} 7 \mathrm{~d}$, were also analysed. The ab initio HFR calculations showed only small mixing. The IC fitting was unfruitful, due to the increase in the number of parameters above the number of experimental energy levels. More detailed calculations are necessary to answer this open question.

\subsection{Transition probabilities}

Transition probabilities, displayed in Fig. 2, obtained for 54 lines of $\mathrm{Pb}$ III with wavelengths in the range 1000 and $30000 \AA$ are displayed in column three of Table III, while columns one and two give the transitions and corresponding

Table II. Parameters resulting from the least square fitting of the intermediate coupling calculations.

\begin{tabular}{llll}
\hline Configuration & & Parameters $\left(\mathrm{cm}^{1}\right)$ & \\
\hline $6 \mathrm{~s} 6 \mathrm{p}$ & $E_{\mathrm{av}}=77729.6$ & $\mathrm{G}^{1}(6 \mathrm{~s}, 6 \mathrm{p})=29954(48762)$ & $\zeta_{6 \mathrm{p}}=12174(11181)$ \\
$6 \mathrm{~s} 7 \mathrm{p}$ & $E_{\mathrm{av}}=174675.2$ & $\mathrm{G}^{1}(6 \mathrm{~s}, 7 \mathrm{p})=2255(3064)$ & $\zeta_{7 \mathrm{p}}=3508(3064)$ \\
$6 \mathrm{~s} 8 \mathrm{p}$ & $\mathrm{E}_{\mathrm{av}}=208358.0$ & $\mathrm{G}^{1}(6 \mathrm{~s}, 8 \mathrm{p})=833(2138)$ & \\
$6 \mathrm{~s} 7 \mathrm{~s}$ & $\mathrm{E}_{\mathrm{av}}=151008.3$ & $\mathrm{G}^{0}(6 \mathrm{~s}, 7 \mathrm{~s})=1403(1356)$ \\
$6 \mathrm{~s} 8 \mathrm{~s}$ & $\mathrm{E}_{\mathrm{av}}=198248.0$ & $\mathrm{G}^{0}(6 \mathrm{~s}, 8 \mathrm{~s})=762(2978)$ & \\
$6 \mathrm{~s} 7 \mathrm{~d}$ & $\mathrm{E}_{\mathrm{av}}=202150.4$ & $\mathrm{G}^{2}(6 \mathrm{~s}, 7 \mathrm{~d})=3632(3164)$ & $\zeta_{7 \mathrm{~d}}=258(189)$ \\
$6 \mathrm{~s} 6 \mathrm{~d}+6 \mathrm{p}^{2}$ & $\mathrm{E}_{\mathrm{av}}=159046.2$ & $\mathrm{G}^{2}(6 \mathrm{~s}, 6 \mathrm{~d})=7347(9778)$ & $\zeta_{6 \mathrm{~d}}=611(443)$ \\
& $\mathrm{E}_{\mathrm{av}}=164460.6$ & $\mathrm{~F}^{2}(6 \mathrm{p}, 6 \mathrm{p})=31998(39207)$ & $\zeta_{6 \mathrm{p}}=11709(11132)$ \\
& & $\mathrm{R}^{1}(6 \mathrm{~s}, 6 \mathrm{~d}, 6 \mathrm{p}, 6 \mathrm{p})=18995(30526)$ & \\
\hline
\end{tabular}

Values in parenthesis are ab initio HFR results.

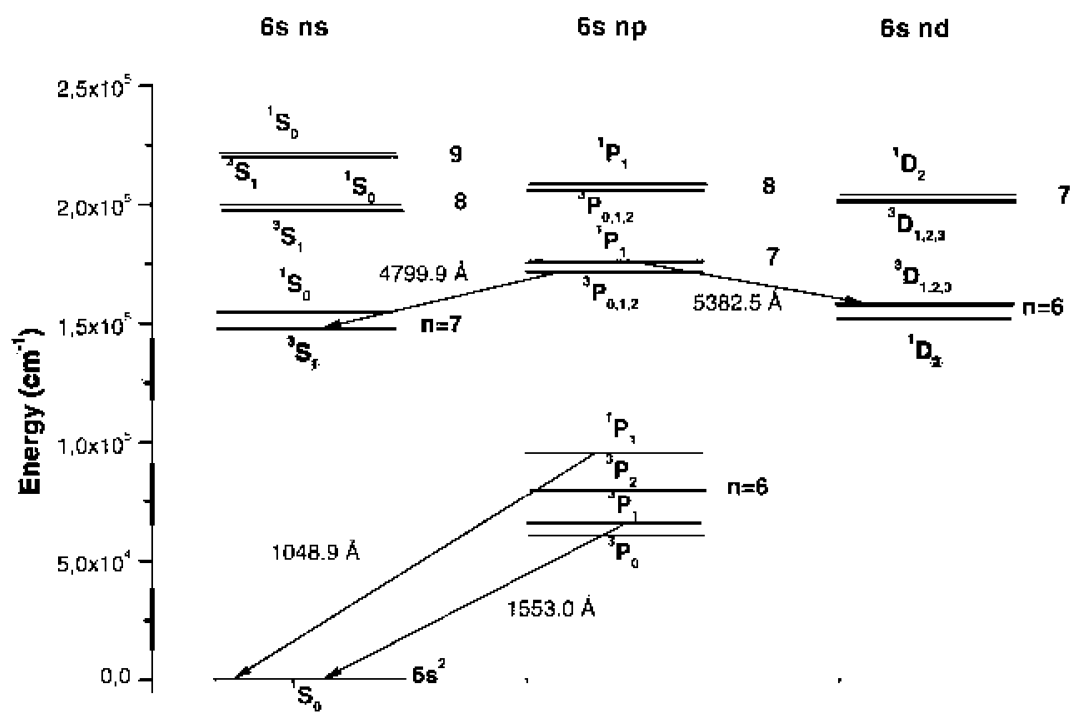

Fig. 2. Partial energy level diagram for $\mathrm{Pb}$ III showing some transitions studied in this work. 
Table III. Transition Probabilities of some Pb III lines.

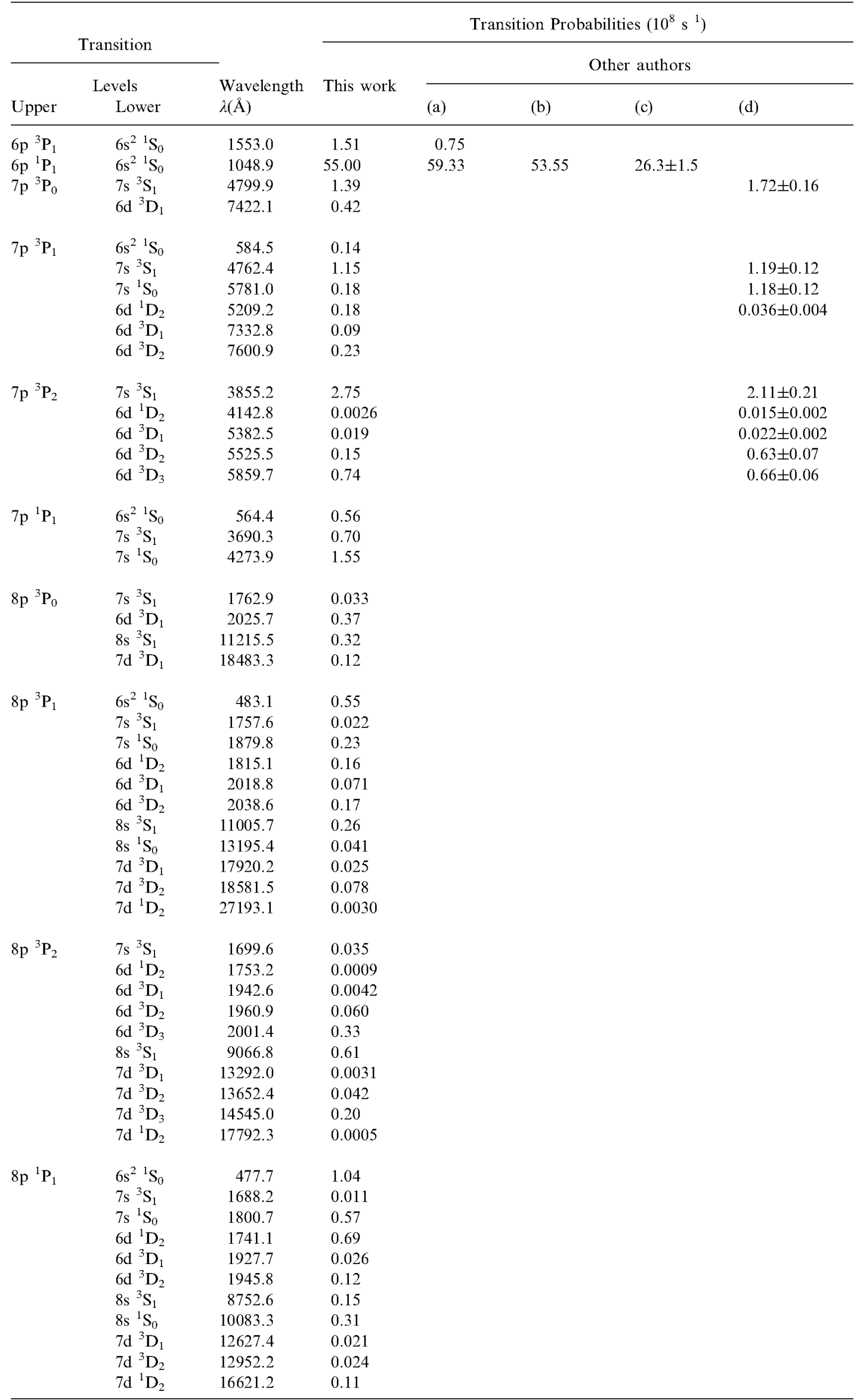

${ }^{\mathrm{a}}$ Migdalek and Baylis (1985).

${ }^{\mathrm{b}}$ Warner (1968).

'Pinnington et al. (1988).

${ }^{\mathrm{d}}$ Colón et al. (1999). 
wavelengths, respectively. The remaining columns give the theoretical (Migdalek and Baylis [4] and Warner [13]) and experimental (Pinnington et al. [7] and Colón et al. [1]) transition probability values to be found in the bibliography.

These values, although in agreement with the rare experimental data, present some noticeable discrepancies: The resonant transition $6 \mathrm{p}^{1} \mathrm{P}_{1}$ to $6 \mathrm{~s}^{2}{ }^{1} \mathrm{~S}_{\mathbf{0}}$ is twice the experimental value. This discrepancy can be reduced using a set of calculations including a potential model to represent core polarisation by Migdalek and Baylis [4]. The $7 \mathrm{p}^{3} \mathrm{P}_{1}$ to $7 \mathrm{~s}{ }^{1} \mathrm{~S}_{\text {。 }}$ transition probability is an order of magnitude smaller than in the experiment. In this case there is a forbidden dipole transition. The existence of this transition is a further clear evidence of configurations mixing detected in our work. However, small contributions of other excited configurations not included in our work, due to the increase in the number of parameters above the number of experimental energy levels, can induce a large effect in the calculation of transition probabilities.

\section{Conclusions}

This work provides theoretical transition probabilities for transitions arising from $6 s 6 \mathrm{p}, 6 \mathrm{~s} 7 \mathrm{p}$ and $6 \mathrm{~s} 8 \mathrm{p}$ configurations, for which no previous values were known. We have also studied the interaction of ${ }^{1} \mathrm{D}_{2}$ levels from $6 \mathrm{~s} 6 \mathrm{~d}+6 \mathrm{p}^{2}$ configurations. 